\title{
Usage of pedestrian overpass in Akure, Nigeria
}

\author{
Samuel Oluwaseyi Olorunfemi", Adetayo Olaniyi Adeniran and Feyisola Olajire Akinsehinwa
}

\begin{abstract}
Background: This study addressed the safety challenge, motivation, and utilization factors regarding the usage of the pedestrian overpass by different people of dissimilar ages alongside Oba Adeshida road at Oja-Oba (Oba market) in Akure, Ondo State, Nigeria. It addressed the following objectives: determined the value of the pedestrian overpass as used by people of different ages; examined the reasons for using the pedestrian overpass in Akure; and examined the performance level of a pedestrian overpass in Akure.

Methods: In total, 384 users (who used the bridge) were purposively sampled for questionnaire administration, but 324 users participated in the questionnaire, which included multiple-choice and open-ended questions. Also, personal observation was employed for queue analysis. The "Semantic Differential Scale" and single-server queue system for the single queue were employed for data analysis.

Conclusions: In Akure, there was low or no usage of the pedestrian overpass when the road median was made use of metal and low concrete; but when the road median was made use of high concrete barrier, there was high usage of the pedestrian overpass. It also revealed that the engineering design of the pedestrian overpass is low compared to the contemporary design solutions in addressing the urban societal needs. The pedestrian overpass was used frequently and every day because it provides access to the car park, market, and central mosque. The performance of the pedestrian overpass in Akure is 105\% which indicates that the pedestrian overpass is over-utilized by a pedestrian. It is recommended that there is a need to construct another pedestrian overpass to enhance the efficiency of the structure. The existing and future pedestrian overpass should be redesigned to constitute interesting aesthetics and architectural solutions that could harmonize with the environment and enhance flow of the disabled persons.
\end{abstract}

Keywords: Pedestrian overpass, Semantic differential scale, Queue system, Akure, Nigeria

\section{Background}

Urban space as a whole consists of structures and open areas where all urban activities are perceived by the inhabitants of the city. In other words, these spaces are where the activities in the lives of the urban dwellers take place. They include places for housing, working, entertainment, transportation, and recreation (Arslan Selçuk and Er Akan 2019).

Hasan and Napiah (2017) posits that mobility have been in existence from the time immemorial, and have

*Correspondence: soolorunfemi@futa.edu.ng

Department of Logistics and Transport Technology, Federal University of Technology Akure, Akure, Nigeria been improved in recent times. With the advancement of technology, increased motorization and urbanization, human beings are having more complex issues such as mobility challenge among pedestrians and other road users. Mobility challenges have negative implication on billions of people across the world; in fact Lucas and Jones (2012) revealed that up to $90 \%$ of households are being deprived of adequate transport to realize basic social and development needs. Simultaneously, it was revealed in the Economist Intelligence Unit (2007) that transport and congestion are the most serious challenges facing megacities. Parnell and Pieterse (2014) predicted in their study that 350 million people and more will live in African cities by 2030, but the region will receive 
below $5 \%$ of global outlay in transport infrastructure (UN Habitat 2013).

The survival and development for upholding the urban population are essential on mobility, and it cannot be efficient without proper planning for public transport such as minibuses, taxis, and motorbikes which enhance the conveyance of people rapidly within urban cities, particularly the Central Business Districts (CBDs). In the CBDs, the use of the pedestrian overpass is important. A pedestrian overpass was one of the objects that appeared in space along with the increasing level of urbanization.

The essence of executing this solution was, firstly, to ensure pedestrian safety and, secondly, to realize uninterrupted vehicle traffic flow. Therefore, the current definition of a pedestrian overpass indicates that it is a perpendicular separation device employed to detach pedestrians from road vehicular traffic without threat of accident especially when crossing (Ribbens 1996). In all aspects of urban dwellers, they must be able to cover a particular space and make use of the provided infrastructures. However, only the existence of suitable functional, technical, aesthetic reinforcements and the components can enable people to use the infrastructure in the best possible way.

The components for reinforcing are not meant to only meet the needs of the citizenry but also have psychological effects on them (Arroya et al. 2018). The dominant means of transportation is road transport which relates to road users, particularly the pedestrians. The dominant challenge impeding the preference of pedestrians for walking is traffic safety (Keyvanfar et al. 2018; Rahman et al. 2019; Shaaban 2019).

Pedestrians are mostly exposed to danger whenever they cross the road. This accounts for a significant proportion of major fatalities that occur among pedestrians, amounting to about $75 \%$ in built-up areas and $50 \%$ in non-built-up areas. The major cause of accident occurrence among pedestrians is failure to give way for other road users (Miśkiewicz 2019; Bartoszewski and Lessear 2017). Pedestrian crossing is known to cause congestion (NuktaRamadani et al. 2017). According to Binti Kadzim (2012), a pedestrian overpass is a significant solution for safety of pedestrian crossing. It is an approach of increasing road network capacity (Binti Kadzim 2012; Cohn and Sperling 2016; Biliszczuk et al. 2020). Pedestrian overpass will provide that pedestrians can cross the road safely for their various trip purposes. Pedestrian overpass should be both "aesthetic" and "functional" (North Seattle College 2019).

In both urban and landscape design studies, there is a need for a variety of structural elements that meet the physical needs of the population and are necessary for their understanding, safety and comfort in terms of health and a clean environment. These elements are defined as urban elements, and they should be compatible with other elements and improve the visual quality of the landscape design as a whole when used correctly (Altınçekiç and Koç 2003). Among these elements are pedestrian overpasses that provide pedestrian access for transport and enhance safety for users. Pedestrian overpasses must have an aesthetic value, and should be able to accommodate different categories of activities. This situation determines the value placed by pedestrian to the overpass (Biliszczuk et al. 2020; Eyre 2002, Idelberger 2011; Flaga and Januszkiewicz 2011). Pedestrian overpass should be designed and used as collision-free crossings (Jamroz et al. 2014) especially at major roads (heavily traffic roads), and at intersections to prevent critical hazards to pedestrians, and prevent delays for vehicles.

Various instances of functional solutions for pedestrian overpasses over roads can be listed as well as the attempts of classifying such constructions can be taken up considering their secondary function-apart from the basic one, i.e., ensuring safety for pedestrian, pedestrians and cycling traffic in cities, or providing the possibility of reaching dangerous and attractive landscape spots located in open spaces (Aksu 2014; Dietrich 1998; Biliszczuk et al. 2001; Idelberger 2011; Salamak and Fross 2016). In the urbanized area (city), the following can be identified:

i. Pedestrian overpasses over roads, such as the "BP Pedestrian overpass" in Chicago (USA), the "Ponte Segunda Circular Bridge" in Portugal, and the "Lunchtsingel Bridge" in Holland;

ii. Pedestrian overpasses with water elements and over wetlands, such as the Pedestrian overpass and footbridge in Media City, England, the Cirkelbroen Bridge in Denmark, the Iceland Bicycle Bridge in Iceland, the Golden Garland Bridge and Melkweg Bridge in Holland and the Merchant Square Footbridge, and Millennium Bridge in London.

iii. Pedestrian overpasses with railway and road components, such as the "Promenade Plantee" and the "High Line Park" in Paris, the "Vance Creek Bridge" in Washington State, the "Kinzua Bridge State Park" in Pennsylvania, and the "Walkway over the Hudson" in New York. All these overpasses are built in open areas and are architecturally outstanding, and harmoniously blended into the natural landscape (Idelberger 2011; Salamak and Fross 2016).

The pedestrian overpass that was situated alongside Oba Adeshida road at the Oja-Oba (Oba market) was constructed in 1992 (Osagie 2021). For many years, the 
overpass was not used because pedestrians could easily cross to either side of the road because the median railings (made use of metal) were broken in many parts (see Fig. 1). There is a high concentration of human and vehicular movement along the Oba-Adesida road which results to the erection of pedestrian overpass and metallic median so as to reduce the level of pedestrian crossing along the road. Over a long period of time the metallic median barrier have either been abused or destroyed by residents. Many times, it was discovered that road users mostly pedestrian jump over these railings in other to cross to the other side of the road with some going as far as cutting the metal item to pave way for their passage, with obvious neglect for the pedestrian overpass. Some of these pedestrians endangered their lives as they could easily be knocked down by on-coming vehicle.

However, there usage of the constructed pedestrian overpass was not efficient over a long time as most pedestrians prefer roadside crossing which still cause vehicle traffic jam. To overcome the issue of vehicular traffic jam, there was a need for an optimum use of pedestrian overpass which results to the erection of the concrete median barrier. Given the fact that concrete median barrier in Oba-Adesida road has enhanced the compulsory usage of pedestrian overpass than when the median barrier was made with metal, it has been noticed that there is high concentration of both human and vehicular traffic before and after approaching the median.

Despite the safety and traffic challenges that resulted to the erection of concrete median barrier which forced many pedestrians to make use of the overpass regardless of their age, a preliminary survey that was conducted by the authors revealed that majority of the pedestrians were not happy with the erection of the concrete median barrier and the forceful usage of the pedestrian overpass. Though this survey was conducted immediately, the median barrier was erected; hence, the negative perception of pedestrian to the usage of pedestrian overpass may reduce overtime.

According to the studies conducted by Gimsing (1997), Flaga and Januszkiewicz (2011), Keil (2013), Chen and Duan (2014), Ivan et al. (2019), Jamroz et al. (2014), Kasuga (2014), Arroya et al. (2018), and Congiu et al. (2019), most pedestrians were expose to road accident, and found that the authority of modern cities are constructing pedestrian overpasses to provide comfortable and safe passage for pedestrians. There are evidences that some types of facilities are generally disliked by pedestrians, which results to a high incidence of informal road crossing behavior, away from crossing facilities (Demiroz et al. 2015; Sinclair and Zuidgeest 2016; Obeng-Atuah et al. 2017; Anciaes and Jones 2018). Also, studies have addressed the challenges of pedestrian overpasses based on the following:

(1) Safety in crossing roads and passing over other obstacles in pedestrian traffic (NuktaRamadani et al. 2017; Demiroz et al. 2015; Jamroz et al. 2014);

(2) Technology, building materials, and durability of the constructed pedestrian overpass (Gimsing 1997; Chen and Duan 2014);

(3) The comfort of users (vibration frequency) (Banaś 2020; Cross et al. 2013; Lievens et al. 2016);

(4) Adapting architectural form and structure to the surrounding space (Biliszczuk et al. 2001; Eyre 2002; Aksu 2014; Salamak and Fross 2016).

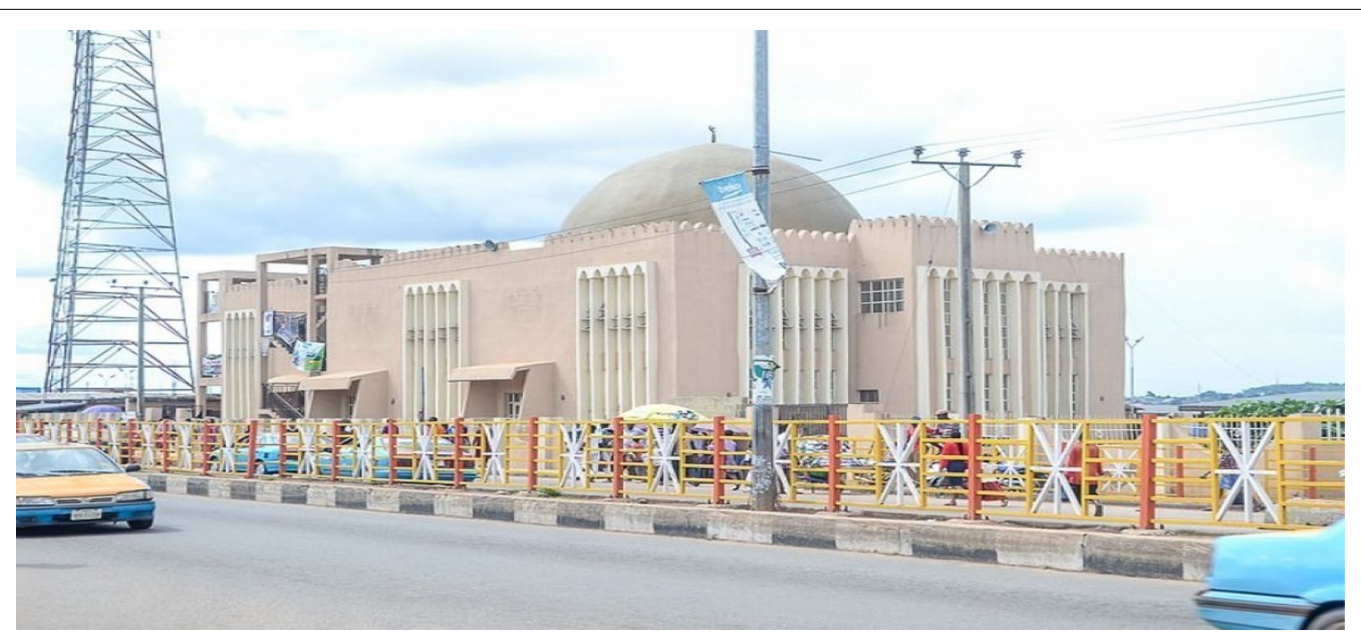

Fig. 1 Metallic median barrier along Oba-Adesida road in Akure. Source: Authors' work 
There is a research lacuna in assessing the opinions of users as regarding the functionality of pedestrian overpass in cities with respect to functionality, aesthetic, and components in Nigeria, especially in Akure. Also, there is a research lacuna on the performance analysis of pedestrian overpass with respect to the utilization capacity of pedestrian overpass. All these are the basis for this study as safety of pedestrians cannot be ignored in transportation planning and policy, and the design for transport infrastructures. On this note, this study is aimed at assessing the usage of pedestrian overpass in Akure, Nigeria.

The objectives of the study are to determine the value placed by pedestrians on the overpass as it is used by people of different ages in Akure; to examine the reasons for using pedestrian overpass in Akure; and examine the performance level of pedestrian overpass in Akure. The purpose of this study is to reveal the preferences of Akure residents and visitors in terms of the usage of pedestrian overpass. Another importance is to reveal the design, safety, comfort, aesthetics, symbolic element and importance for transportation of a pedestrian overpass and its capacity utilization. This study is essential because the assessment of pedestrian overpass will enhance policy recommendations regarding infrastructural development and maintenance plan.

\section{Methods}

This study employed hypotheses testing, which is entailed in quantitative research method or quantitative part of mixed research methods; hence, mixed research method was adopted to address the problems of this study (Yin 2018; Frels and Onwuegbuzie 2013; Creswell 2012). Furthermore, a mixed research method was selected for this study because the study employed both interviews and questionnaires to elicit primary data from respondents (Jasti and Kodali 2014; Verdinelli and Scagnoli 2013). Also, personal observation was employed for primary data collection.

This study adopted the case study research design because it focused on the lived experiences and perceptions of the respondents (Shona 2020; Yin 2018; Yazan 2015; Vohra 2014; Tsang 2013). In this study, the perception of pedestrians in Akure was explored on the users' opinion on the role and importance of pedestrian overpass in Akure, Nigeria. This study targeted pedestrians in Akure, Nigeria, because they are suitable in examining the role and importance of pedestrian overpass in Akure.

To determine the appropriate sample size for a large (infinite) population and an uncertain number population, judgment was made about the confidence level and the maximum error allowance (Zikmund 2003). Because of the constraints of resources, the budget for large samples might be difficult; hence, the researcher adopts the error term of 0.05 . This method of sample size determination is appropriate for non-probabilistic convenience sampling. Hence, the estimation of the population by the sample size may not be necessary. Therefore, the use of a nonparametric test is suitable. The equation applied for sample size is shown below.

$$
n=\frac{Z^{2}}{4 E^{2}}
$$

where, $n=$ Sample size for pedestrian, $Z=Z$ score for the $95 \%$ level of confidence is $1.96, E=$ Maximum acceptable error $=0.05$.

95\% confidence level at 0.05 maximum error was chosen because of the time consciousness of air passengers.

When inserting the values into the sample size equation, it resulted in a sample size of 384 . The researcher, therefore, divides the sample size equally for the pedestrian as this will be considered for questionnaire distribution. The aggregate sample size determined was 384 , as shown:

$$
\begin{aligned}
& n=\frac{1.96^{2}}{4(0.05)^{2}} \\
& n=\frac{3.84}{0.01} \\
& n=384
\end{aligned}
$$

However, the researcher ensured that the return of the questionnaires was not less than the 384 sample size. This research is survey research, and the sampling technique is purposive (non-probability) sampling. The sampling itself is convenience sampling. According to Saunders et al. (2012), there are no other criteria to the sampling method except that people or respondents were available and willing to participate. In this study, questionnaires and interviews were employed for primary data collection. Three hundred and eighty-four formal questionnaires were distributed to pedestrians at the pedestrian overpass in Akure. In an interview approach for collecting primary data particularly for the mixed, the instruments for data collection were face-to-face interviews, questionnaires, and personal observation. The nature of the questionnaire was open-ended and closed-ended responses.

The Akure pedestrian overpass located along Oba Adeshida road at the Oja-Oba (Oba market) was constructed in 1992, during the administration of late Bamidele Ishole Olumilua (Osagie 2021), where area field studies were carried out in the study and constitute the main material of the study. Observations and questionnaire studies, photographs taken during field studies, and SPSS 21.0 statistical program were other materials used 
Table 1 Response rate

\begin{tabular}{lcl}
\hline Questionnaires & Frequency & Percent \\
\hline Valid & & \\
Returned valid questionnaires & 324 & 84.4 \\
Questionnaires not returned & 60 & 16.6 \\
Total & 384 &
\end{tabular}

Source: Field Survey, 2021

in the study. Akure pedestrian overpass, which is located in the city center of Akure, has been chosen as the study area (see Fig. 1). The reasons for choosing the Akure pedestrian overpass are as follows: It is at the city center of Akure, it is used intensively by pedestrians, there are bus stops that provide transportation to other locations, and it provides access to the parking lot. Steel was used in the construction of the pedestrian overpass, and the floor is of cast concrete.

Some of the issues concerning the pedestrian overpass include:

Technical problems: These include paint problems, spills on the overpass which is caused by the nature of steel material, lack of binding materials, and damage caused by the users, as well as the convenience of using the overpass for everyone.

Aesthetic problems: There were no design criteria for the bridge that could add value to the space. It is simply a pedestrian overpass made of steel carriers and steel labs.

Taking into account the pedestrian location along the frequently used pedestrian route and also in an important cultural and landscape place, i.e., in the market center of Akure, the study was carried out to identify the expectations and motives of those using the aforementioned pedestrian overpass across the road.

According to Adanikin et al. (2017), the utilization factor $(R)=\frac{\text { Averagearrivalrate }(\lambda)}{\text { Averageservicerate }(\mu)}$. Here, $R$ is the fraction of time the server is working (called the utility factor). The timedependent behavior of this system will be considered firstly, then the limiting behavior. Let $R_{n}(t)$ denote the probability that at time $t$ there are $n$ passengers in the system. For a single queue $(M / M / 1)$ system, the expected queue length $L$ is given by $=\frac{R}{1-R}$ (Adeniran and Kanyio 2019).

\section{Results}

\section{The response rate of respondents}

The study sought to gather information from users of the pedestrian overpass in Akure. Table 1 shows that a total of three hundred and eighty-four (384) questionnaires were distributed to pedestrians in Akure, and 324 questionnaires were collected having filled. This translated to a response rate of $84.4 \%$. According to Mugenda and
Mugenda (2003), a response rate of $50 \%$ is adequate for data analysis and reporting; a rate of $60 \%$ is good and a response rate of $70 \%$ and over is excellent. It could therefore be said that the $84.4 \%$ response rate achieved in this survey is very good.

\section{Descriptive analysis of respondents' demographic characteristics}

In the study, the mixed research (questionnaire) method was applied in the study area to determine the current usage status of the pedestrian overpass in Akure and to determine the feasibility of pedestrian overpass in the city. For the study, a questionnaire-based field survey was administered, and face-to-face interviews were carried out to determine the reasons the people of Akure city used the pedestrian overpass and how frequently they used it.

The purpose of the research method was to qualify the numerical information. Before the questionnaire questions were prepared, on-site observations were made by going to the study area. The studies of Arslan Selçuk and Er Akan (2019), Hasan and Napiah (2017), Kuskun (2002), Mumcu, (2002), and Denli (1997) were checked during the design of the questionnaire.

During the questionnaire design, care was taken to ask clear and understandable questions that could be answered, while still respecting people's privacy. The questionnaires were designed for individuals over the age of 18 , with the idea that they would take a more conscientious approach. The questionnaire was carried out between 10 a.m. and 4 p.m. on July 23, 2021, with 384 respondents that were sampled. The purposive sampling method was used to target the respondents.

The participant who responded to the questionnaire were asked a total of 12 multiple-choice questions and also provided information about their demographic characteristics. Each questionnaire took an average of $10 \mathrm{~min}$. The results of the demographic composition of the 324 people who participated in the survey were as follows:

Gender: 196 (60.5\%) were female and 128 (39.5\%) male. Age: 112 (34.6\%) were aged 18-23 years, 123 (38.0\%) were aged $24-29$ years and 76 (23.5\%) were aged 30 years and above. The average age of the respondents was 29.0 years of age, with a standard deviation of 9.76 years. At least half of the respondents were not older than 25 . The youngest respondent was 18 years old, whereas the oldest one was 63 years old.

Educational status: 10 (3.09\%) had completed primary school, 3 (0.93\%) middle school, 45 (13.9\%) high school, 211 (65.1\%) university and 43 (13.3\%) post-graduate education. Occupational status: 68 (20.9\%) were architects/ engineers, 126 (38.9\%) were students, and 118 (36.4\%) were in other occupations (See Table 2). The survey was 
Table 2 Demographic characteristics of respondents

\begin{tabular}{lcc}
\hline Variables & Frequency & Percentage \\
\hline Gender & 196 & 60.5 \\
Female & 128 & 39.5 \\
Male & & \\
Age & 112 & 34.6 \\
18-23 years & 123 & 38 \\
24-29years & 76 & 23.5 \\
30 years above & & \\
Education status & 10 & 3.09 \\
Primary school & 3 & 0.93 \\
Middle school & 45 & 13.9 \\
High school & 211 & 65.1 \\
University & 43 & 13.3 \\
Post-graduate education & & \\
Occupational status & 68 & 20.9 \\
Architects/engineers & 126 & 38.9 \\
Students & 118 & 36.4 \\
Other occupations &
\end{tabular}

Source: Authors' work

conducted with the participation of 324 individuals, of whom 68 were architects/engineers, 126 were students, and 118 were from other professions.

\section{Value of the pedestrian overpass as used by people of different ages in Akure}

Value assessments were facilitated by reminder photographs used during the survey (Figs. 2 and 3). Figure 2 is snapped when the road median was made use of metal and low concrete, while Fig. 3a-c is snapped in recent times when the median was made use of a high concrete barrier. The usage of pedestrian overpass was also examined based on people of different ages. The significant difference in the distribution of responses was checked using the Chi-square test of independence. For all analyses, the maximum permissible error class $\alpha=0.05$ was adopted, and $p \leq 0.05$ was considered statistically significant.

The pictures revealed that when the road median was made use of metal and low concrete, there was low usage of the pedestrian overpass; also when the road median was made use of high concrete barrier, there was high usage of pedestrian overpass. As shown in Fig. 3b, c, it can be seen that commercial activities are happening around the pedestrian overpass; this is because of the closeness to the market. In fact, commercial activities are done inside the overpass, and the same time the disabled persons are sitting down asking for alms; these hinder the free flow of pedestrians in the overpass.

When asked about the frequency of using the pedestrian overpass, out of the total of 324 participants, 166 (51.2\%) answered "Everyday" and "Frequently," 45 (13.89\%) "1-2 times per month," 33 (10.2\%) "Rarely," 23 (7.1\%), "1-2 times per week," 13 (4.01\%), and " $2-3$ times per week." The pedestrian overpass is generally accessible and apart from the car park, it also provides access to the market, central mosque. Hence, it was reasonable to analyze who the main users of the pedestrian overpass are and how frequently they use it.

Statistical analysis was also carried out using the Chi-square test of independence. To this end, the respondents were divided into two groups, where the division point was the median value for the age variable (25 years of age). Some categories related to frequencies of using the pedestrian overpass were also combined so that the smallest percentage of cells in the developed cross-table had an expected number of less than 5 . The respondents under 25 years of age rarely used the pedestrian overpass (64\%), and the percentage

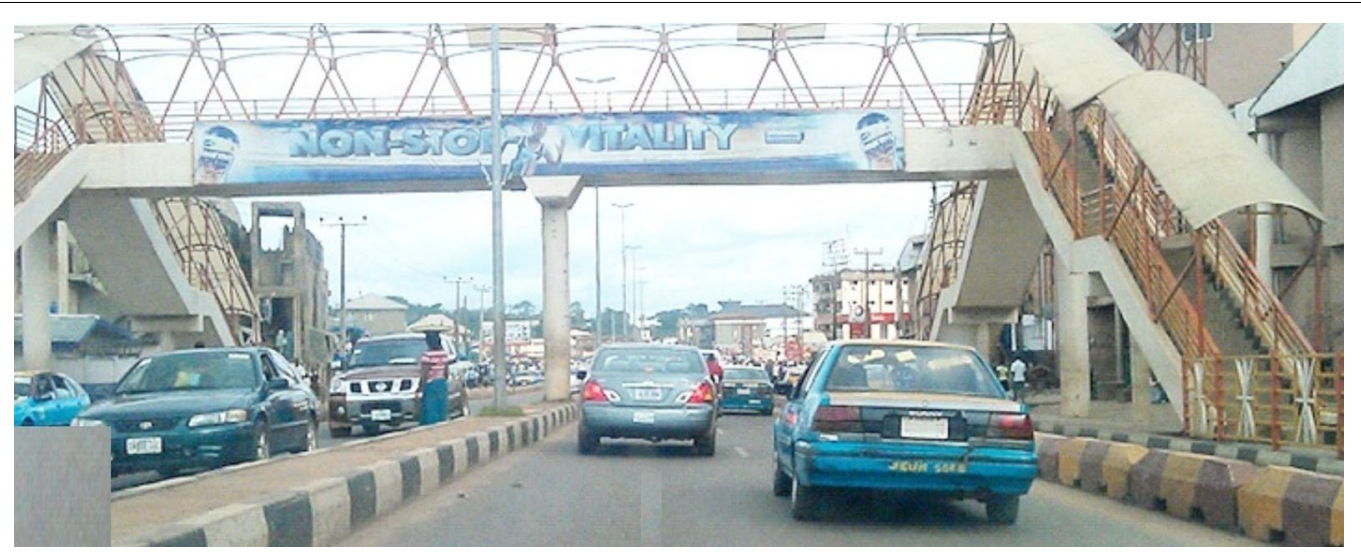

Fig. 2 Photographs used in the survey. Source: Authors' shot 

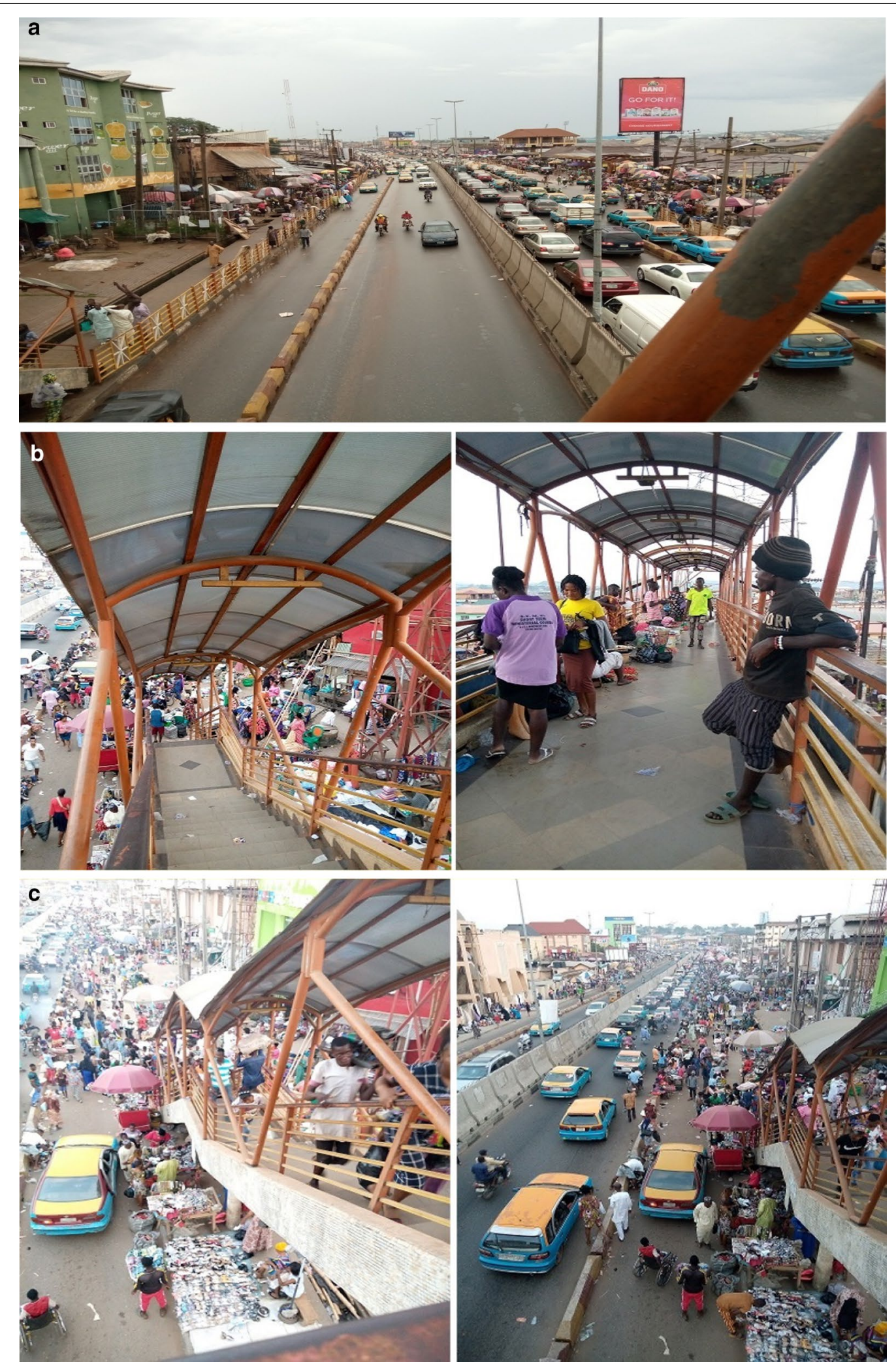

Fig. 3 a-c Photographs used in the survey. Source: Authors' shot 
Table 3 Distribution of responses broken down by age

\begin{tabular}{llll}
\hline Frequency of usage & Score & \multicolumn{2}{l}{ Age } \\
\cline { 3 - 4 } & & $\leq \mathbf{2 5}$ years & > 25 years \\
\hline $\begin{array}{l}\text { Frequently or every } \\
\text { day }\end{array}$ & \%Within age & 64.2 & 40.4 \\
1-2 times per month & \%Within age & 13.4 & 15.8 \\
Few times per week & \%Within age & 10.4 & 12.3 \\
Rarely & \%Within age & 11.9 & 31.6 \\
Pearson Chi-Square & & $x^{2}=9.16 ;$ Sig. $=0.027$ & \\
\hline
\end{tabular}

Source: own study

of such population aged over 25 was smaller and amounted to $40 \%$. The percentage of people using the pedestrian overpass often and daily in the group under or at the age of 25 was $12 \%$, whereas among older people, it was $32 \%$. The differences are statistically significant $(p=0.027)$ (see Table 3).

The statistical analysis using the Chi-square test of independence showed a statistically significant relationship between social status and the frequency of using the pedestrian overpass $(p=0.018)$. The answer frequently used was indicated by $44 \%$ of the respondents from the group of engineers, $62 \%$ by students; and by other respondents $49 \%$ (see Table 4 ).

\section{Reasons for using the pedestrian overpass in Akure}

When asked about the direction of moving through the pedestrian overpass in the first place, $76.0 \%$ of the respondents answered "To go to the market," followed by 9.3\% in second place with "To go to the city center," $7.8 \%$ in the third place with "To go home," $2.3 \%$ "To go to the hospital", and finally, $0.8 \%$ responded "To go to the university" (see Fig. 4).

As has been confirmed by the conducted research, the primary purpose of using the pedestrian overpass is to ensure safety. Out of the total number of 324 participants, $36.4 \%$ provided the answer "For safety and security," 27.9\% "There is no alternative," $20.2 \%$ "It's a convenient route," $10.1 \%$ "It's the way to the coast," and $1.6 \%$ "It's the way to the parking lot" (see Fig. 5).

Ensuring safety on the one hand and smooth traffic flow of motor vehicles on the other remains the essential purpose of constructing pedestrian overpasses. However, not all of the respondents indicated safety as the reason for choosing the discussed pedestrian overpass, other reasons were as follows: no alternative, convenience, and

Table 4 Distribution of responses broken down by social status

\begin{tabular}{|c|c|c|c|c|}
\hline \multirow[t]{2}{*}{ Frequency of use } & \multirow[t]{2}{*}{ Score } & \multicolumn{3}{|l|}{ Social status (job) } \\
\hline & & Engineer-architect & Student & Other \\
\hline Frequently or every day & $\%$ Within social status & 44.4 & 62.0 & 48.9 \\
\hline $1-2$ times per month & $\%$ Within social status & 29.6 & 12.0 & 8.5 \\
\hline Few times per week & $\%$ Within social status & 18.5 & 10.0 & 8.5 \\
\hline Rarely & $\%$ Within social status & 7.4 & 16.0 & 34.0 \\
\hline Pearson Chi-Square & & \multicolumn{3}{|l|}{$x^{2}=15.34 ;$ Sig. $=0.018$} \\
\hline
\end{tabular}

Source: own study

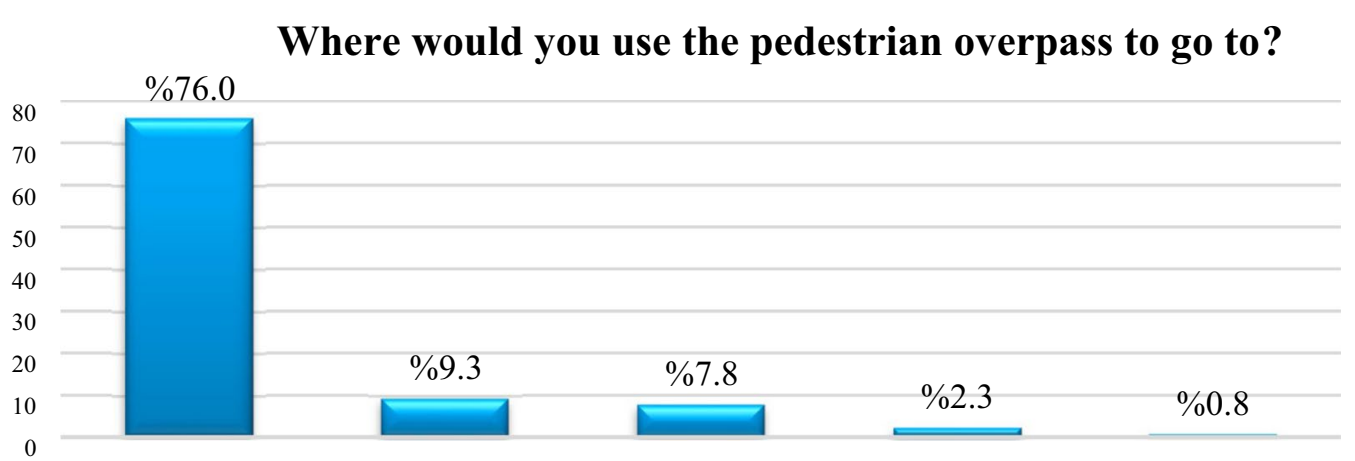

To go the market To go to the city To go home To go to the hospitalTo go the University

Fig. 4 Reasons for using the pedestrian overpass 


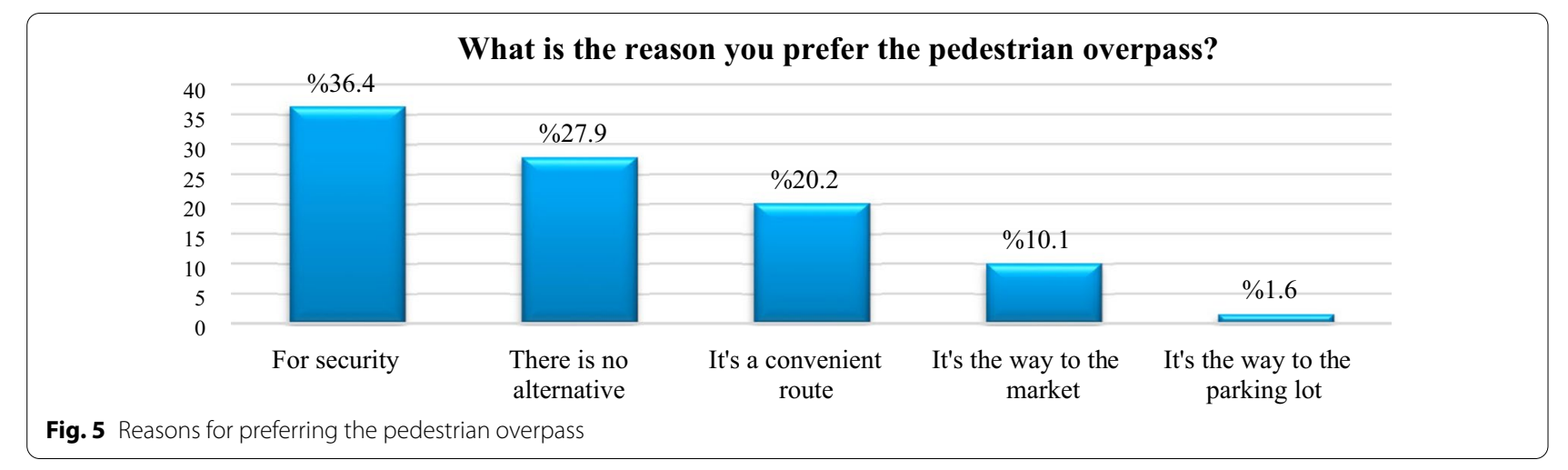

Table 5 Reasons for choosing versus frequency of using a pedestrian overpass

\begin{tabular}{llll}
\hline Frequency of use & & Reasons & For security \\
\cline { 3 - 3 } & & For security & 30.80 \\
\hline Rarely & \%Within reasons & 59.20 & 23.10 \\
$1-2$ times per month & \%Within reasons & 12.20 & 7.70 \\
Few times per week & \%Within reasons & 12.20 & 38.50 \\
Frequently or every day & \%Within reasons & 16.30 & $x^{2}=9.96 ;$ Sig. $=0.019$ \\
Pearson Chi-Square & & & \\
\hline
\end{tabular}

Source: own study

the way to reach the destination (market, parking lot). Indeed, the traffic of motor vehicles on the highway is so intense that virtually all along its length in Akure, it is required to use either a pedestrian overpass to get to the other side.

Such a possibility of reaching the sea must be also attractive for the pedestrians in every respect (apart from safety, the equally important factors are comfort, harmony with the surroundings, and an attractive architectural form of the facility).

The respondents who chose the way through an overpass for safety reasons generally used it rarely (59\%), and the percentage of such people among those selecting a pedestrian overpass for another reason was smaller and amounted to $31 \%$. Such individuals often used a pedestrian overpass daily or often (39\%). The analysis using the Chi-square test of independence showed that the discussed differences are statistically significant $(p=0.019)$ (see Table 5).

The statistical analysis did not show any significant correlation between the respondent's age and the choice of safety as the reason for traveling through a pedestrian overpass (See Table 6).

When asked the question, "Do you consider the pedestrian overpass safe over the road crossing?", as many as $35.5 \%$ of the respondents answered "No"; however, their vast majority consider it safe (64.5\%) (see Fig. 6).
Table 6 Reasons for the choice versus age

\begin{tabular}{lll}
\hline Age & $\mathbf{2} \mathbf{2 5}$ years & $\mathbf{2 5}$ years \\
\hline Reason score & & 77.2 \\
$\begin{array}{l}\text { For security } \\
\text { \% Within age }\end{array}$ & 80.6 & 22.8 \\
$\begin{array}{l}\text { Other } \\
\text { \% Within age }\end{array}$ & 19.4 & \\
Pearson Chi-square & $x^{2}=0.22 ;$ Sig. $=0.643$ & \\
\hline
\end{tabular}

Source: own study

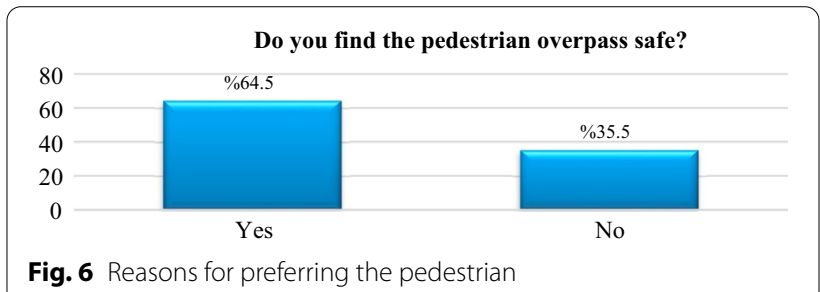

As shown in Fig. 7a, b, the pictures revealed that the pedestrian overpass was not accessible for special people (e.g., for people moving in wheelchairs). This may cause difficulty for the disabled persons. 

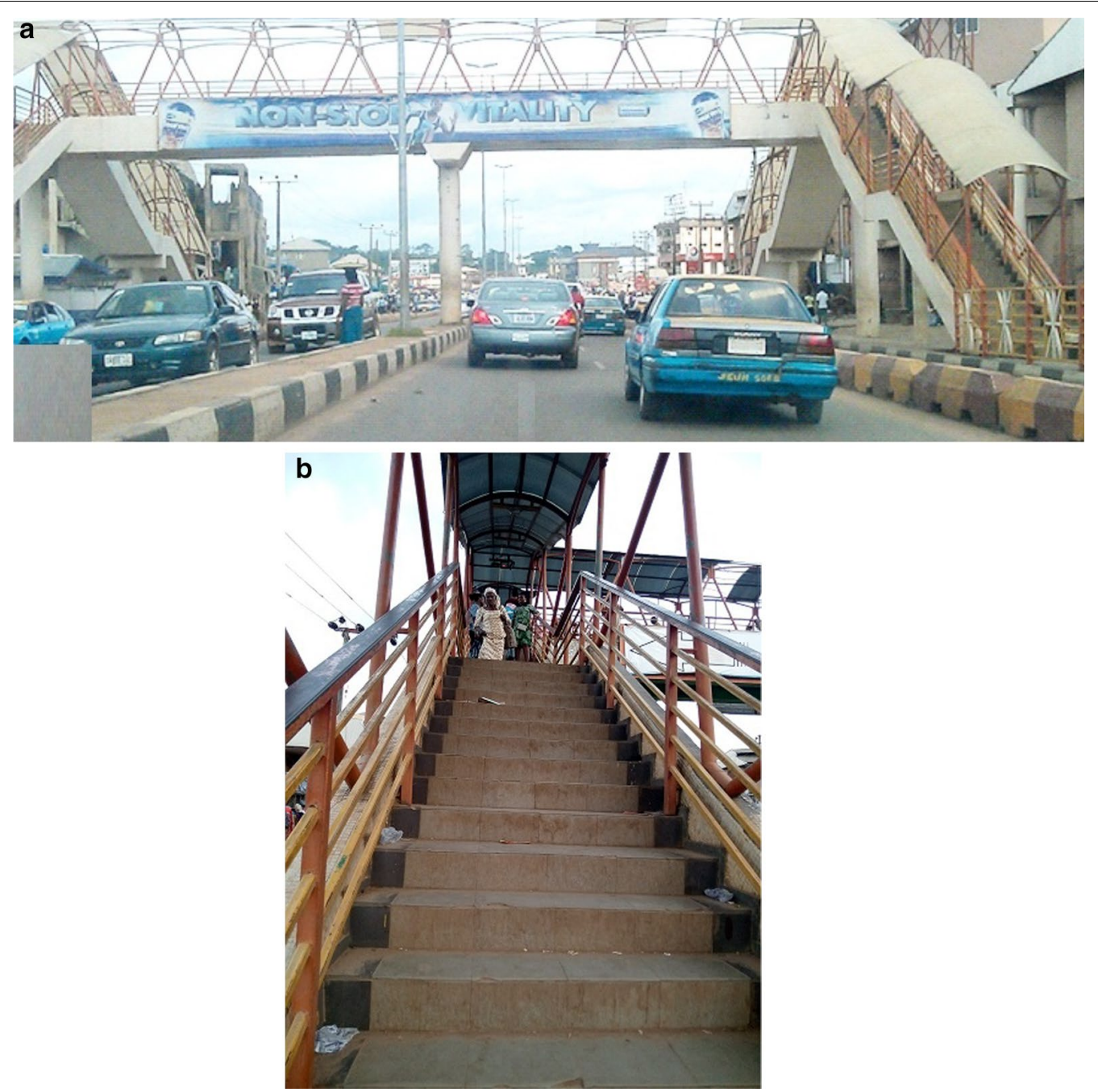

Fig. 7 a The pedestrian overpass suspended over the highway in Akure. $\mathbf{b}$ The nature of staircase of pedestrian overpass in Akure

Taking into account the applied research methodology and the evaluation system of criteria used in the survey, the following research results were obtained. The average value of each criterion was calculated according to the results of the survey. To determine whether there is a relationship between the criteria, the values given by the 324 people participating in the questionnaire for each criterion are analyzed in Table 7.

The existence of a relationship among the criteria of "functional," "harmonious," "aesthetic," "attractive," "special," "memorable," and "safe" was assessed by applying the Spearman correlation test. According to the Spearman correlation, a significant positive correlation was found among all the criteria $(p<0.01)$. Among the criteria, the highest correlation coefficient values were found for "functional" with "harmonious," "harmonious" with "aesthetic," "harmonious" with "safe," "aesthetic" with "attractive," "attractive" with "special" and "special" with "memorable" (see Table 7). The expected result was that all the criteria were interdependent because they all supported each other.

The performance level of the pedestrian overpass in Akure The queuing theory is employed in this study as follows:

(a) Average arrival rate to the staircase $(\lambda)=726$ pedestrians/h

$$
\lambda=\frac{726}{3600}=0.2017
$$

(b) Average service or climbing rate $(\mu)=693$ pedestrians/h 
Table 7 Relationship values among the criteria

\begin{tabular}{|c|c|c|c|c|c|c|c|c|}
\hline Relationship criteria & Functional & Regular & Aesthetic & Attractive & Private & Unforgettable & Secure & \\
\hline \multirow[t]{2}{*}{ Functional } & Cor. coe. Sig. level & 1.000 & & & & & & \\
\hline & & - & & & & & & \\
\hline \multirow[t]{2}{*}{ Regular } & Cor. coe. Sig. level & $0.569^{\prime \prime}$ & 1.000 & & & & & \\
\hline & & 0.000 & - & & & & & \\
\hline \multirow[t]{2}{*}{ Aesthetic } & Cor. coe. Sig. level & $0.457^{\prime \prime}$ & $0.613^{\prime \prime}$ & 1.000 & & & & \\
\hline & & 0.000 & 0.000 & - & & & & \\
\hline \multirow[t]{2}{*}{ Attractive } & Cor. coe. Sig. level & $0.403^{\prime \prime}$ & $0.502^{\prime \prime}$ & $0.825^{\prime \prime}$ & 1.000 & & & \\
\hline & & 0.000 & 0.000 & 0.000 & - & & & \\
\hline \multirow[t]{2}{*}{ Private } & Cor. coe. Sig. level & $0.279^{\prime \prime}$ & $0.447^{\prime \prime}$ & $0.633^{\prime \prime}$ & $0.670^{\prime \prime}$ & 1.000 & & \\
\hline & & 0.000 & 0.000 & 0.000 & 0.000 & - & & \\
\hline \multirow[t]{2}{*}{ Unforgettable } & Cor. coe. Sig. level & $0.303^{\prime \prime}$ & $0.324^{\prime \prime}$ & $0.573^{\prime \prime}$ & $0.576^{\prime \prime}$ & 0.721 & 1.000 & \\
\hline & & 0.000 & 0.000 & 0.000 & 0.000 & 0.000 & - & \\
\hline \multirow[t]{2}{*}{ Secure } & Cor. coe. Sig. level & $0.550^{\prime \prime}$ & $0.574^{\prime \prime}$ & $0.522^{\prime \prime}$ & $0.503^{\prime \prime}$ & $0.424^{\prime \prime}$ & $0.464^{\prime \prime}$ & 1.000 \\
\hline & & 0.000 & 0.000 & 0.000 & 0.000 & 0.000 & 0.000 & - \\
\hline
\end{tabular}

Source: own study

Sig. level: Significance level, Cor. Coe.: Correlation coefficient

$$
\mu=\frac{693}{3600}=0.1925
$$

(c) Average interval between arrival $=\frac{1}{\lambda}$

$$
=\frac{1}{0.2017}=4.9579 \mathrm{~s}
$$

(d) Average interval between service rate $=\frac{1}{\mu}$

$$
=\frac{1}{0.1925}=5.1948 \mathrm{~s}
$$

(e) Average queue length $=\frac{\lambda^{2}}{\mu(\mu-\lambda)}$

$$
=\frac{0.2017^{2}}{0.1925(0.1925-0.2017)}=\frac{0.0407}{-0.0018}=22.61 \text { Pedestrians }
$$

(f) Average waiting time in the queue $=\frac{\lambda}{\mu(\mu-\lambda)}$

$$
\begin{aligned}
& =\frac{0.2017}{0.1925(0.1925-0.2017)}=\frac{0.2017}{-0.0018} \\
& =112.06 \mathrm{~s}=1.87 \mathrm{~min}
\end{aligned}
$$

(g) Efficiency of pedestrian overpass based on it utilization $(R)=\frac{\lambda}{\mu}$

$$
R=\frac{0.2017}{0.1925}=1.05
$$

It is important to note that the utilization factor is greater than $1(R>1)$ (Adeniran and Kanyio 2019; Adan and Resing 2015; Ademoh and Anosike 2014); hence, the performance of the pedestrian overpass in Akure is 105\% which indicates that the pedestrian overpass is over-utilized by pedestrians.

\section{Discussion}

Concerning the value of the pedestrian overpass as used by people of different ages in Akure, the study revealed that the road median was initially made of metal and low concrete and as a result, the pedestrian overpass was majorly used by beggars as hideout. While in recent times when the median was made use of a high concrete barrier, the pedestrians made use of the overpass, although there are categories of pedestrians that made use of the overpass mainly. Without any doubt, the OjaOba market is a traffic attraction zone; hence, there will be conflict between pedestrians and vehicle traffic if the transport infrastructures are not properly planned. Urbanization processes resulted in the need to search for solutions allowing the separation of pedestrians and vehicle traffic. Unfortunately, the analyzed object differs from the contemporary design solutions, which often fit into the surrounding landscape, and their implementation uses modern engineering techniques and construction materials.

The study found that pedestrians that are below 25 years made use of the overpass the most, and they belong to the student category. This agrees with the findings of Banaś (2020) which found that young categories make use the pedestrian overpass in Jordan than the adults and elderly categories. This study also revealed that the pedestrian overpass was used frequently. This is similar with the findings of Sharples and Fletcher (2001), Anciaes and Jones (2018), Sinclair and Zuidgeest (2016). The major users of the pedestrian overpass made use of it majorly to have access to the market. They also considered the usage of the pedestrian overpass because of 
safety and security. It is pertinent to note that the major advantage of pedestrian overpasses is that they separate pedestrians from road traffic. As a result, pedestrian overpasses (and stopping pedestrians from crossing the roadway at grade) may reduce pedestrian accidents by up to $90 \%$ (Miśkiewicz et al. 2017). This is in agreement with the finding of Abojaradeh (2013), which found that pedestrian overpasses have a positive impact and potential to minimize the number of pedestrian fatalities. This infrastructure enhance the reduction in crime rates (Sharples et al. 2019; Anciaes and Jones 2018; Sinclair and Zuidgeest 2016; James et al. 2005).

The results of this study have emphasized that this overpass could carry a semantic and symbolic element in addition to the binding element. In parallel with the positive examples abroad, the pedestrian overpass should be re-evaluated within a correct concept, format, and scenario for its environment. The pedestrian overpass must be recreated and, by using a correct design approach, a new pedestrian overpass with identity must be generated. From a study of pedestrian overpass crossings conducted in Bangladesh (Dhaka), it was revealed that $71 \%$ of pedestrians prefer an underpass rather than using footbridge. In Poland, the study of Bartoszewski and Lessear (1979) also confirmed that pedestrians prefer to use underpasses to overpass. This study also found that the pedestrian overpass was not accessible for special people (e.g., for people moving in wheelchairs) which is not the same in the developed countries.

Nonetheless, the local conditions should be taken into consideration, which impose the only correct solution (in the presented case, the topography is decisive). The reasons pedestrians do not use road crossing facilities are insufficient security, the fact that they are time-consuming, poor entrances, hawker's problems, discomfort, the long walk required, etc. (NuktaRamadani et al. 2017). First of all, a good spatial composition should be prepared, and spatial components and items should be brought together in a harmonious way (Mumcu 2002). The composition of this architecture is formed by bringing the elements together and deliberately arranging them to create a semantically, functionally, and visually satisfactory whole (Abojaradeh 2013).

Space is not created solely by its existence. The activities within the space and those who use it exist. For this reason, the more activities provided in a space, the more open it is to use. The research confirmed that the presented pedestrian overpass is necessary for accessing the Oja-Oba market in Akure. Shortly, it is necessary to consider the construction of a new pedestrian overpass having a modified architectural form, because apart from its basic function, i.e., safety in pedestrian traffic, it should also meet an aesthetic function and confirm the cultural identity of the city. It should be considered to construct a pedestrian overpass of the twenty-first century using modern technologies and taking into account the tradition of the location (Wang et al. 2019; Napiah 2017; Anciaes et al. 2016; Footbridge Construction 2014; Matsumoto et al. 2011; Trani 2011; Bastani 2009; Gür 1996).

The performance of the pedestrian overpass in Akure is $105 \%$ which indicates that the pedestrian overpass is over-utilized by a pedestrian. This findings does not corroborate the finding of Abojaradeh (2013) in Jordan which revealed that the utilization of pedestrian overpass is low, and over $60 \%$ of pedestrians choose not to use pedestrian overpasses for various reasons (Banaś 2020). This study found that male respondents make use of the overpass than females, while the study of Banaś (2020) found that females use the pedestrian overpass in Jordan than males and children more than adults.

\section{Conclusions}

This study is aimed at assessing the usage of pedestrian overpass in Akure, Nigeria, with a view to determining the value placed by pedestrians on the overpass as it is used by people of different ages; examining the reasons for using pedestrian overpass in Akure; and examining the performance level of pedestrian overpass in Akure.

For this study, information was gathered from users of the pedestrian overpass in Akure. Apart from the personal observations, the questionnaire was distributed and elicited from 324 respondents. The descriptive analysis revealed that majority of the respondents was female representing 60.5\%, they were aged between 18 and 29 years representing $72.6 \%$, they were mostly high school certificate holders representing $65.1 \%$ and consist of students representing $38.9 \%$ and engaged in other occupations representing $36.4 \%$.

Concerning the value of pedestrian overpass as used by people of different ages in Akure, the pictures revealed that when the road median was made use of metal and low concrete, there was low usage of the pedestrian overpass; also when the road median was made use of high concrete barrier, there was high usage of pedestrian overpass. It was also revealed that the engineering design of the pedestrian overpass is low compared to the contemporary design solutions in addressing the urban societal needs. Regarding the frequency of usage, the pedestrian overpass, about $51 \%$ of the participants make use of the pedestrian overpass frequently and every day. This is because the pedestrian overpass provides access to the car park, market, and central mosque.

The statistical analysis (Chi-square test) revealed statistically significant relationship between age and the frequency of using the pedestrian overpass $(p=0.027)$ such that the respondents under 25 years of age rarely used the 
pedestrian overpass, and the percentage of population aged over 25 was smaller and amounted to $40 \%$. The statistical analysis (Chi-square test) revealed a statistically significant relationship between social status and the frequency of using the pedestrian overpass $(p=0.018)$. Concerning the reasons for using the pedestrian overpass in Akure, majority of the respondent (76\%) made use of the pedestrian overpass to have access to the market, and to ensure safety and security (36.4\%). The performance of the pedestrian overpass in Akure is 105\% which indicates that the pedestrian overpass is over-utilized by a pedestrian.

Based on these findings, the following recommendations were drawn:

1. As the pedestrian uses the pedestrian overpass in Akure more frequently, they will begin to notice other features of the pedestrian overpass. Therefore, the pedestrian overpass should be redesigned to constitute interesting aesthetics and architectural solutions that could harmonize with the environment and enhance flow of the disabled persons.

2. The pedestrian overpass should be closely monitored so as to prevent any form of commercial activities and alms begging that could hinder free movement of pedestrians.

3. The pedestrian overpass in Akure should be roofed to enhance safety and protection against adverse weather conditions, and at the same time reducing the incidents of throwing objects into the highway. In addition, an area for observation and photography can be created on the overpass to encourage people in these activities. Seating areas can also be provided for pedestrians to sit and explore the nature of vehicular movements.

4. Finally, the performance of the pedestrian overpass in Akure is over-utilized. Hence, there is a need to construct another overpass to enhance the efficiency of the structure.

\section{Abbreviation \\ CBDs: Central Business Districts.}

\section{Authors' contributions}

SOO designed the introduction and methods; AOA designed the study, analyzed the data and proofread the article; FOA proofread and edited the study. All authors have read and approved the manuscript.

\section{Funding}

N/A.

\section{Availability of data and materials}

The datasets generated and/or analyzed during the current study are available from the corresponding author on reasonable request, but cannot be made publicly available in order not to go against the declaration of confidentiality made to the participants.

\section{Declarations}

Ethics approval and consent to participate N/A.

\section{Consent for publication}

N/A.

\section{Competing interests}

The author declares that there is no competing interest.

Received: 1 November 2021 Accepted: 3 December 2021

Published online: 20 December 2021

\section{References}

Abojaradeh M (2013) Evaluation of pedestrian overpass and pedestrian safety in Jordan. Civil Environ Res 3:66-78

Adan I, Resing J (2015) Queuing systems. Department of Mathematics and Computer Science, Eindhoven University of Technology, Eindhoven

Adanikin A, Olutaiwo A, Obafemi T (2017) Performance study of University of Ado Ekiti (UNAD) transit shuttle buses. Am J Traffic Transp Eng 2(5):67-73. https://doi.org/10.11648/j.ajtte.20170205.12

Ademoh NA, Anosike EN (2014) Queuing modelling of air transport passengers of Nnamdi Azikiwe International Airport Abuja, Nigeria using multi-server approach. Middle East J Sci Res 21(12):2326-2338. https:// doi.org/10.5829/idosi.mejsr.2014.21.12.21807

Adeniran AO, Kanyio OA (2019) Quantitative model of single-server queue system. Indian J Eng 16:177-183

Aderamo AJ (2012) Urban transportation problems and challenges in Nigeria: a planner's view. Prime J 2(3):198-203

Aksu Ö (2014) Yaya Üst Geçitlerinde Tasarım Ölçütlerinin Irdelenmesi. Istanbul Üniversitesi Orman Fakültesi Derg 64:12-28

Alınçekiç H, Koç H (2003) Peyzaj Tasarımında Kent Mobilyalarıve Kalite Beklentileri. II. In: Proceedings of the Uluslararası Kent Mobilyaları Sempozyumu, Istanbul, Turkey, 24-27 April 2003 (in Turkish)

Anciaes PA, Jones P (2018) Estimating preferences for different types of pedestrian crossing facilities. Transp Res Part F: Traffic Psychol Behav 52:222-237

Anciaes PR, Jones P, Mindell JS (2016) Community severance: where is it found and at what cost? Transp Rev 36(3):293-317

Arroya R, Mars L, RuizT (2018) Perception of pedestrian and cyclist environments, travel behaviors, and social networks. Sustainability 10:3241

Arslan Selçuk S, Er Akan A (2019) Assessing sidewalk and corridor walkability in developing countries. Sustainability 11:3865

Banaś A (2020) Ocena komfortu pieszego nakładkach. Case study [Assessment of comfort on the pedestrian overpass. Case study]. Builder 8:277

Bartoszewski J, Lessear S (1979) Tunnels and underground passages in cities. WKŁ, Warszawa

Bartoszewski J, Lessear S (2017) Tunele i Przej'scia Podziemne w Miastach [Tunnels and Underground Passages in Cities]. Warszawa, Poland, WKŁ (In Polish)

Bastani P (2009) A queuing model of hospital congestion. MSc. A thesis submitted to the Department of Mathematics Simon Fraser University

Biliszczuk J, Machelski C, Onysyk J, Prabucki P, Węgrzyniak M (2001) Pedestrian overpass as landmarks on the highway. Inzynierial Build 11:643-648

Biliszczuk J, Onysyk J, Prabucki P, Toczkiewicz R (2020) Kładki jako elementy infrastruktury zwi ekszaj ace bezpiecze 'nstwo pieszych [Footbridges as infrastructure elements increasing pedestrian safety]. Inzynieria I Bud., 6, 269-273 (In Polish)

Binti Kadzim HN (2012) Study on effectiveness of pedestrian overpass utilization. Bachelor's Thesis, Faculty of Civil Engineering \& Earth Resources University Malaysia Pahang, Pahang, Malaysia. http://umpir.ump.edu.my/ id/eprint/14470/1/FKASA\%20-\%20NURUL\%20HIDAYAH\%2OKADZIM.PDF

Chen W, Duan L (2014) Handbook of international bridge engineering. Tylor \& Francis Group, New York, NY

Cohn J, Sperling E (2016) Improving pedestrian and bicycle connectivity during rehabilitation of existing bridges. In: Transportation Research Board. Pedestrian and Bicycle Information Center. Chapel Hill, NC, USA, pp 1-13 
Congiu T, Sotgiu G, Castiglia P, Azara A, Piana A, Saderi L, Dettori M (2019) Built environment features and pedestrian accidents: an Italian retrospective study. Sustainability 11:1064

Creswell J (2012) Qualitative inquiry and research design: choosing among five approaches. SAGE, Los Angeles, CA

Cross EJ, Koo KY, Brownjohn JMW, Worden K (2013) Long-term monitoring and data analysis of the Tamar bridge. Mech Syst Signal Process 35:16-34

Demiroz YI, Onelcin P, Alver Y (2015) Illegal road crossing behavior of pedestrians at overpass locations: factors affecting gap acceptance, crossing times and overpass use. Accid Anal Prevent 80:220-228

Denli S (1997) The analysis of graphical indication meanings regarding semiology. Master's Thesis, Institute of Social Sciences, Atatürk University, Erzurum, Turkey

Dietrich R (1998) Faszination Brücken. Callwey, München

Economist Intelligence Unit (2007) Democracy Index 2007. ElU, London

Eyre J (2002) Aesthetics of footbridge design. In: Proceedings of the international conference on the design and dynamic behaviour of pedestrian overpass, Paris, France, 20-22 Nov 2002, pp 96-103

Flaga K, Januszkiewicz K (2011) On the aesthetic and technical efficiency of current arched pedestrian overpass. In: Proceedings of the international conference on the design and dynamic behaviour of pedestrian overpass, Wrocław, Poland, 6-8 July 2011, pp 126-137

Footbridge Construction (2014) A challenge for innovation and sustainability. In: Proceedings of the international conference on the design and dynamic behaviour of pedestrian overpass, London, UK, 16-18 July 2014. pp 86-95

Frels RK, Onwuegbuzie AJ (2013) Administering quantitative instruments with qualitative interviews: a mixed research approach. J Counsel Develop JCD 91(2). https://doi.org/10.1002/j.1556-6676.2013.00085.x

Gimsing N (1997) Cable supported bridges_concept and design. Wiley, New York, NY

Gür ŞÖ (1996) Gür Yayıncılık, Trabzon

Hasan R, Napiah M (2017) Utilization of footbridges: influential factors and improvement proposals. J Adv Trans Stud 43:43-60

Idelberger K (2011) The world of pedestrian overpass: from the utilitarian to the spectacular. Ernst \& Sohn, Berlin

Ivan K, Benedek J, Ciobanu SM (2019) School-aged pedestrian-vehicle crash vulnerability. Sustainability 11:1214

James E, Millington A, Tomlinson P (2005) Understanding community severance. Part 1: views of practitioners and communities. Report to the UK Department for Transport, United Kingdom

Jamroz K, Gaca S, Michalski L, Kieć M, Budzyński M, Gumińska L, Kustra W, Mackun T, Oskarbska L, Rychlewska J (2014) Protection of pedestrians guidelines for pedestrian traffic organizer. National Road Safety Council, Gdansk

Jasti NVK, Kodali R (2014) A literature review of empirical research methodology in lean manufacturing. Int J Oper Prod Manag 34:1080-1122. https:// doi.org/10.1108/TJOPM-04-2012-0169

Kasuga A (2014) Footbridge construction - a challenge for innovation and sustainability. In: Proceedings of the international conference on the design and dynamic behaviour of pedestrian overpass, London, UK, 16-18 July 2014, pp 86-95

Keil A (2013) Pedestrian overpass: ramps, walkways, structures. Walter de Gruyter, Berlin

Keyvanfar A, Ferwati MS, Shafaghat A, Lamit HA (2018) Path walkability assessment index model for evaluating and facilitating retail walking using Decision-Tree-Making (DTM) method. Sustainability 10:1035

Kuşkun PA (2002) Research on the use of outdoor furniture in the case of Erzurum. Master's Thesis, Institute of Natural and Applied Sciences, Atatürk University, Erzurum, Turkey

Lievens K, Lombaert G, De Roeck G, Van den Broeck P (2016) Robust design of a TMD for the vibration serviceability of a footbridge. Eng Struct 123:408-418

Lucas K, Jones P (2012) Social impacts and equity issues in transport: an introduction. J Transp Geogr 21:1-3

Matsumoto Y, Maeda S, Iwane Y, Iwata Y (2011) Factors affecting perception thresholds of vertical whole-body vibration in recumbent subjects: gender and age of subjects, and vibration duration. J Sound Vib 330:1810-1828

Miśkiewicz M (2019) Structural response of existing spatial truss roof construction based on Cosserat rod theory. Continuum Mech Thermodyn 31 (4). https://doi.org/10.1007/s00161-018-0660-8

Miśkiewicz M, Pyrzowski Ł, Okraszewska R (2017) Pedestrian and bicycle bridges as examples of safe collision-free road crossings. MATEC Web Conf 122:01005
Mugenda OM, Mugenda AG (2003) Research methods: quantitative and qualitative approaches. Acts Press, Nairobi

Mumcu S (2002) Investigation of place preferences in open spaces in terms of spatial properties: the case of Trabzon. Master's Thesis, Institute of Natural and Applied Sciences, Karadeniz Technical University, Trabzon

Napiah M (2017) Utilization of pedestrian overpass: influential factors and improvement proposals. Adv Transport Stud Int J Sect A 2017:43

North Seattle College (2019) The Seattle Department of Transportation Northgate Pedestrian and Bicycle Bridge Alternative Development and Selection. https://www.seattle.gov/Documents/Departments/SDOT/ BridgeStairsProgram/AlternativeDevelopmentandSelectionFINAL.pdf

NuktaRamadani H, Rahmani H, Gazali AA (2017) Study of efficiency pedestrian overpass crossing in the road of Pangerang Antasari, Banjarmasin. In: Proceedings of the MATEC web of conferences 181, Makassar, Indonesia, 4 Nov 2017

Obeng-Atuah D, Poku-Boansi M, Cobbinah PB (2017) Pedestrian crossing in urban Ghana: safety implications. J Transport Health 5:55-69

Osagie O (2021) 29 Years after Akure Residents begin Use of the Pedestrian overpass. Vintage Press Limited, Matori (Optimized by iNERD360)

Parnell S, Pieterse E (2014) Africa's urban revolution. Zed Press, London

Rahman MS, Abdel-Aty M, Hasan S, Cai Q (2019) Applying data mining techniques to analyze the pedestrian and bicycle crashes at the macroscopic level. In: Proceedings of the Transportation Research Board 98th annual meeting, Washington, DC, USA, 13-17 Oct 2019

Ribbens H (1996) Pedestrian facilities in South Africa: research and practice. Transport Res Board 1538:10-18

Salamak M, Fross K (2016) Bridges in urban planning and architectural culture. Procedia Eng 161:207-212

Saunders M, Lewis P, Thomhil A (2012) Research methods for business students, 6th ed

Shaaban K (2019) Assessing sidewalk and corridor walkability in developing countries. Sustainability 11:3865. https://doi.org/10.3390/su11143865

Sharples JM, Fletcher JP (2001) Pedestrian perceptions of road crossing facilities Scottish Executive Central Research Unit, Edinburgh, United Kingdom. http://www.gov.scot/resource/doc/156816/0042173.pdf. Accessed on 12 July 2021

Sharples J, Albers B, Fraser S (2019) Putting evidence to work: a school's guide to implementation. (Guidance Reports). EEF (Education Endowment Foundation): London. Retrieved from https://discovery.uclac.uk/id/ eprint/10068468/

Shona M (2020) An introduction to research methods. https://www.scribbr. com/category/methodology/

Sinclair M, Zuidgeest M (2016) Investigations into pedestrian crossing choices on Cape Town Freeways. Transport Res F 42:479-494

Trani AA (2011) Introduction to transportation engineering, introduction to queuing theory. Virginia Polytechnic Institute and State University, Blacksburg, pp 2-46

Tsang EWK (2013) Case study methodology: causal explanation, contextualization, and theorizing. J Int Manage 19(195):202. https://doi.org/10.1016/j. intman.2012.08.004

UN Habitat (2013) Planning and design for sustainable urban mobility: global report on human settlements. UN-Habitat, Nairobi

Verdinelli S, Scagnoli NI (2013) Data display in qualitative research. Int J Qualitat Methods 359-381. https://doi.org/10.1177/160940691301200117

Vohra V (2014) Using the multiple case study design to decipher contextual leadership behaviors in Indian organizations. Electron J Bus Res Methods 12:54-65

Wang D, Wu C, Zhang Y, Li S (2019) Study on vertical vibration control of long-span steel footbridge with tuned mass dampers under-pedestrian excitation. J Constr Steel Res 154:84-98

Yazan B (2015) Three approaches to case study methods in education: Yin, Merriam, and Stake. Qual Rep 20(2):134-152

Yin RK (2018) Case study research and applications: design and methods, 6th edn. Sage Publications Inc, Thousand Oaks, CA

Zikmund WG (2003) Exploring marketing research, 8th edn. Thompson Learning/Southwestern, Cincinnati, $\mathrm{OH}$

\section{Publisher's Note}

Springer Nature remains neutral with regard to jurisdictional claims in published maps and institutional affiliations. 